\title{
Análise experimental de treliça tridimensional com correção da excentricidade na ligação estampada usando espaçadores de aço e com polímero reforçado com fibra de sisal
}

\author{
Welington Vital da Silva* ${ }^{1 *}$ Luciano Mendes Bezerra', Cleirton André Silva de \\ Freitas ${ }^{2}$, Francisco F. S. de Morais Júnior ${ }^{2}$ e Brenda A. Távora Ribeiro². \\ ${ }^{1}$ Programa de Pós-graduação em Estruturas e Construção Civil - PECC, \\ Universidade de Brasília, Prédio SG-12, 10 andar, Campus Darcy Ribeiro, CEP: \\ 70910-900, Brasília-DF, welington.vital@gmail.com,Imbz@unb.br \\ ${ }^{2}$ Departamento de Engenharia Civil, Universidade Federal do Cariri, Av. Tenente \\ Raimundo Rocha S/N, Cidade Universitária do Juazeiro do Norte CEP: 70910- \\ 900, Ceará - CE, andre.freitas@ufca.edu.br, fabiojuniorsaraiva@gmail.com, \\ brendadealencartr@gmail.com
}

\section{Experimental analysis of spatial trusses with eccentricity correction on stamped connection using spacers of steel, sisal fiber reinforced polymer}

\begin{abstract}
Resumo
Os sistemas de treliças tridimensionais, desenvolvidos na Europa e nos Estados Unidos a partir da $2 \circ$ Guerra Mundial, surgiram como uma excelente possibilidade estrutural para cobertura de grandes vãos livres. A limitação quanto ao uso dessas estruturas estão relacionadas principalmente à fragilidade dos nós, especificamente os classificados de nós típicos devido à excentricidade gerada pela ligação estampada. Diante disso, foi executado seis protótipos de treliças espaciais com dimensões de $9 \times 6 \mathrm{~m}$, com correção da ligação típica por meio de dois elementos distanciadores, aço e sisal. Os ensaios experimentais mostraram que os distanciadores aumentam aproximadamente $48 \%$ a capacidade resistente da estrutura, evitando principalmente o colapso na ligação. De modo que, nos protótipos com distanciadores o colapso aconteceu por flambagem das barras.
\end{abstract}

Palavras-chave: Treliça tridimensional, Ensaio Experimental, Excentricidade e Sisal.

\section{Abstract}

The special trusses were developed in Europe and United States after the $2^{\text {nd }}$ world war, it raised as an excellent structural system for large spans roof. The limitation of the use is main related to the nodes weakness, specifically at those classified as typical node, whose generates eccentricity in the stamped connections. In view of this, six prototypes of space trusses with dimensions of $9 \times 6 \mathrm{~m}$ were executed, with correction of the typical connection by means of two spacing elements, steel and sisal. Experimental trials have shown that spacers increase approximately $48 \%$ the strength of the structure, mainly avoiding collapse in connection. So, in the prototypes with spacers the collapse occurred by buckling of the bars.

Keywords: Space Trusses, Experimental Testing, Eccentricit and Sisal 


\section{Introdução}

A arquitetura contemporânea é cada vez mais contumaz, em projetos arquitetônicos que necessitam de coberturas com grandes vãos livres, colunas cada vez mais espaçadas e irregulares. Esta tendência tem levado a busca constante por técnicas que viabilizem essa realidade, sobre a perspectiva do tripé fundamental da engenharia estrutural: segurança, economia e durabilidade de forma a ter uma estrutura incólume.

Neste contexto, as estruturas treliçadas tridimensionais apresentam vantagens significativas em relação aos sistemas convencionais de cobertura, permitindo ao projetista maiores possibilidades, tais como: aumento dos vãos (Magalhães e Malite, 1998) e (Souza, 2003); elementos estruturais mais esbeltos e mais leves (Makowski, 1972) e (Ramaswamy, Mick e Suresh, 2002); distribuição de carregamento entre as barras de forma tridimensional (Magalhães e Malite, 1998), (Souza et al., 2009) e (Freitas, Bezerra e Silva, 2011); menores deslocamentos devido à alta rigidez inerente (Souza, 2006); elegante para cobrir amplos espaços (Freitas, 2008); as peças são produzidas em fábricas e posteriormente à montagem acontece no canteiro de obra, com menor tempo de execução (Lanik do Brasil, 2017). Desse modo, as treliças tridimensionais demonstram ser uma alternativa com enorme potencial nesse tipo de construção.

Nesse ínterim, existem diversos tipos de ligações não patenteados no Brasil, sendo que, as mais utilizadas consistem em ligações com nós ditos "típicos" Figura 1. Tal fato é justificado pelo baixo custo e simplicidade de execução (Souza, 2003). Nos modelos de cálculo, as ligações das treliças tridimensionais são consideradas como nós rotulados com cargas axiais centradas e não são fundamentalmente considerados momentos fletores (Freitas et al., 2014) causados pela estampagem das barras próximo à ligação.

De modo, que a montagem da treliça tridimensional com ligação típica utiliza-se a sobreposição de barras estampadas e unidas por um único parafuso indo contra as recomendações da ABNT NBR 8800 (2008). Todavia, este sistema apresenta diversos problemas estruturais (Bezerra et al., 2009), um deles é devido à excentricidade no nó, 
proporcionando a ruptura da ligação devido aos acréscimos de tensões por causa do momento fletor, que corrobora para ruína da ligação com aproveitamento ineficiente da capacidade resistente das barras resultando no colapso da ligação.

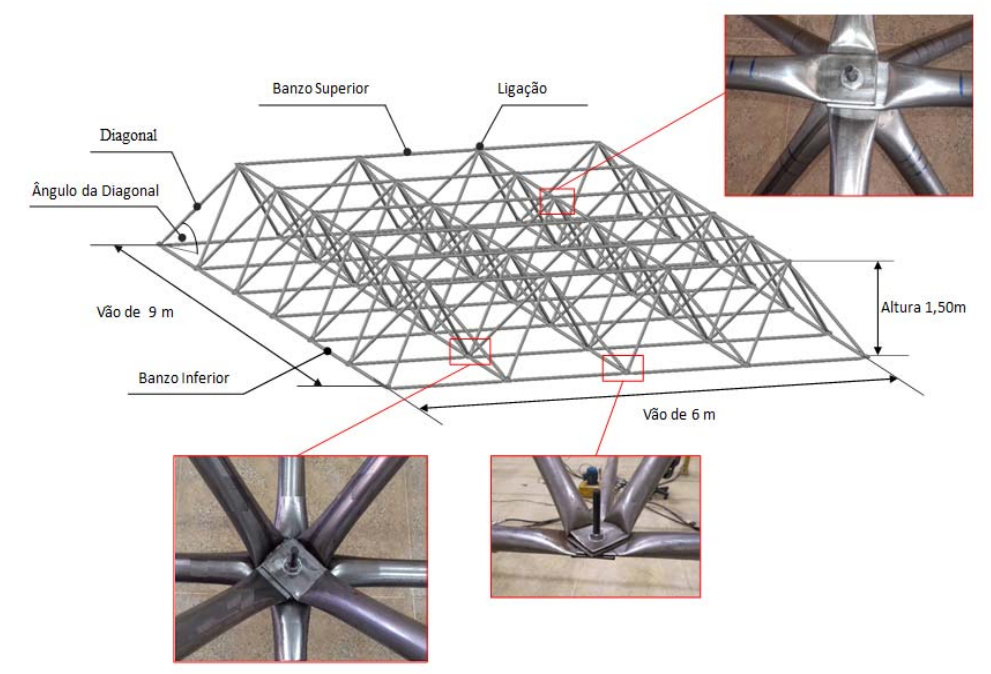

Figura 1- Elementos da treliça tridimensional com nó típico

Dessa forma, para diminuir à excentricidade da ligação e não precisar estampar as barras das treliças tridimensionais, diversas ligações foram desenvolvidas, a fim de garantir estabilidade e resistência ao colapso progressivo. Estas ligações são encontradas no Brasil, Estados Unidos, Canada, Alemanha, Espanha, França, Itália, Inglaterra, Holanda e Singapura (Magalhães e Malite, 1998), (Souza et al., 2009), (Bezerra et al., 2009), (Arekar e Bhavsar, 2013), (El-Shami, Mahmoud e Elabd, 2016), (Wei, Tian e Hao, 2018), (Zeitschrift et al., 2018) conforme Figura 2. Doravante, por esta razão, a representatividade demonstrada por algumas das detentoras das patentes muitas das vezes tem caráter comercial, que nem sempre expressa eficiência da nova ligação (Souza et al., 2009), deveria estar empregado a critérios claros com comprovação de testes em laboratório ou modelos numéricos validados para corroborar a eficiência da ligação (John Chilton, 2000) e (Silva et al., 2018). Outro fator importante que deve ser ressaltado, é que os custos com as ligações patenteadas são mais onerosas em comparação com as ligações típicas que podem inclusive inviabilizar a execução deste sistema de cobertura. Assim, recorre-se na maioria das vezes a opções mais simples e econômicas, como no caso da ligação típica amplamente utilizada devida sua facilidade no processo de fabricação, transporte, aplicação e baixo custo de execução (Chan e Cho, 2005). 


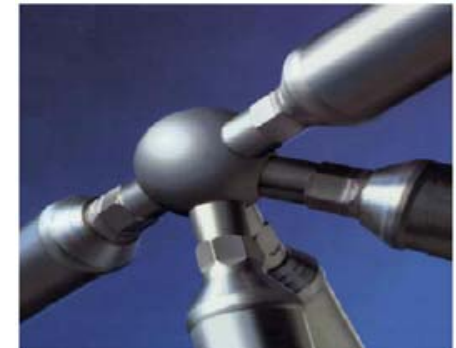

Conexão Orama

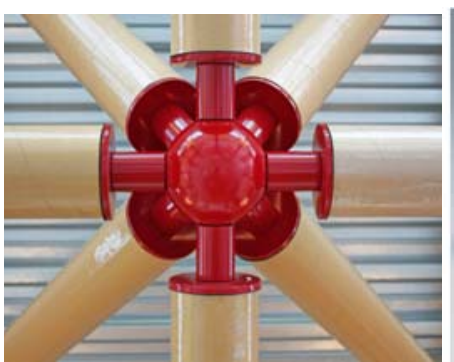

Conexão Octatube

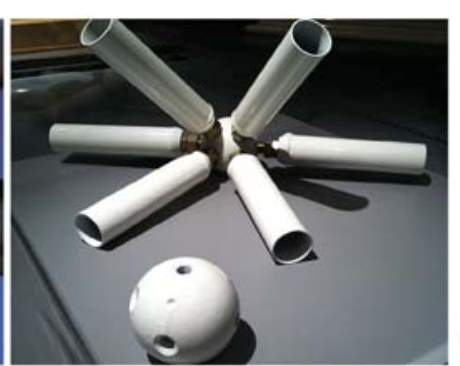

Conexão Ortz system

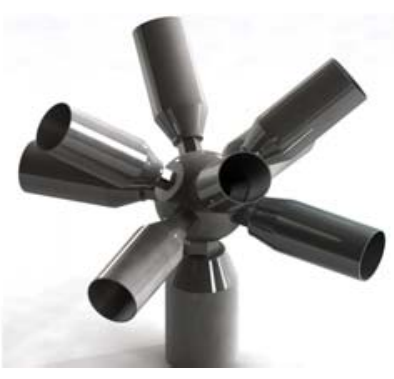

Conexão Mero

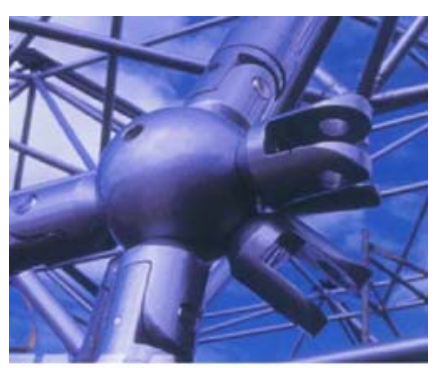

Conexão Axis

Figura 2- Ligações de treliças espaciais com patentes (Souza, 2003) e (Casanova, 2015)

\section{Colapso de treliça tridimensional e nova proposta de solução}

O objetivo deste artigo está relacionado com o fato das treliças tridimensionais apresentarem instabilidades locais (Hill, Blandford e Wang, 1989), especificamente nas ligações do tipo estampadas, que apresentam rotações locais quando solicitadas, ocasionando colapso da ligação (Freitas, 2008), sem o aproveitamento da capacidade resistente das barras (Souza, 2003). Esse problema é explicado pelas mudanças geométricas geradas no modelo (Bezerra et al., 2009), devido à estampagem das barras, ocasionando o surgimento de excentricidade nas ligações (Gioncu, 1985), (Chan e Cho, 2005) e (Freitas et al., 2014) e (Silva et al., 2018).

Originando, acréscimos de tensões e redução da capacidade de carga da estrutura (Freitas, Bezerra e Silva, 2011). Alguns acidentes causados pelo colapso das ligações já foram evidenciados, como o caso do Coliseu Centro Cívico de Hartford que colapsou em janeiro de 1978 (Martin e Delatte, 2001). Onde hospedava um local para vários shows e jogos, a cobertura em treliça tridimensional tinha formato de pirâmides, e era composta por banzos superiores e inferiores com diagonais unidas por ligações parafusadas (Ramaswamy, Mick e Suresh, 2002). O prognóstico do laudo concluiu que a edificação colapsou devido à ruptura abruta da ligação mediante a presença de momentos fletores, por causa de carregamento de neve (Martin e Delatte, 2001) conforme mostra Figura 3a. 
De forma semelhante, no Brasil diversos acidentes também aconteceram devido ao colapso de estruturas tridimensionais (Sampaio, 2004), como por exemplo a cobertura do Centro de Convenções de Manaus apresentado na Figura 3b e 3c (Souza, 2003), (Freitas, 2008) e (Casanova, 2015), a estrutura pesava mais de cem toneladas que desabou em 19 de abril, de 1994 deixando 25 pessoas feridas. No momento da queda, 900 alunos estudavam em 18 salas que funcionava embaixo das arquibancadas do Sambódromo (Nogueira, Varellada, 1994). O laudo desenvolvido pelo Instituto de Criminalística de São Paulo, revelou uma somatória de falhas na concepção do projeto e no cálculo estrutural, por não considerar os esforços adicionais nas barras estampadas da treliça tridimensional.

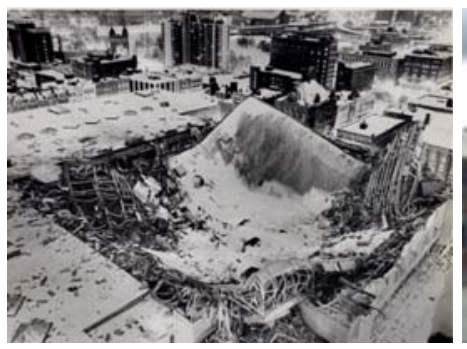

(a)

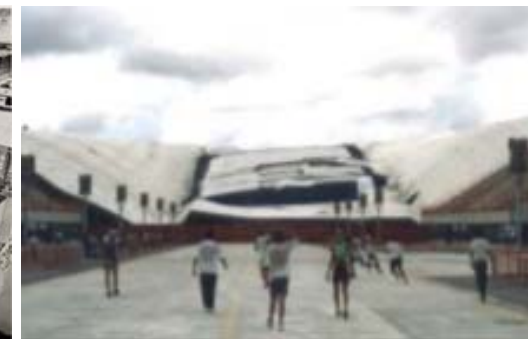

(b)

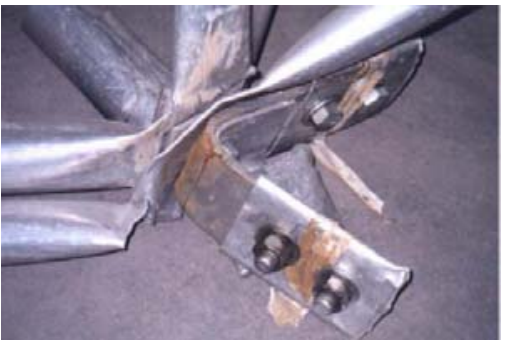

(c)

(a) Colapso da cobertura do Hartford Estados Unidos (Fu, 2016); (b) Colapso da cobertura do Centro de Convenções de Manaus (Souza, 2003); (c) Detalhe do colapso da treliça tridimensional do Centro de Convenções de Manaus (Sampaio, 2004)

Figura 3 - Detalhes de colapso de treliça tridimensional

Diante deste aspecto, uma proposta é apresentada para melhorar a eficiência dos nós típicos de ligações estampadas, que consiste em corrigir a excentricidade inerente a esse detalhe de ligação, conforme apresenta Figura 4 (Freitas, 2008), através de um elemento distanciador de baixo custo e fácil aplicabilidade.

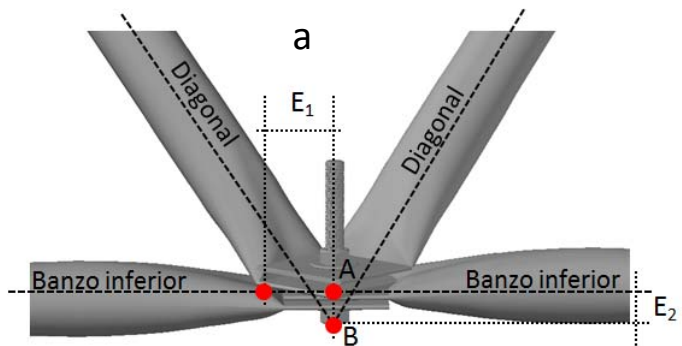

(a) Conexão com excentricidade

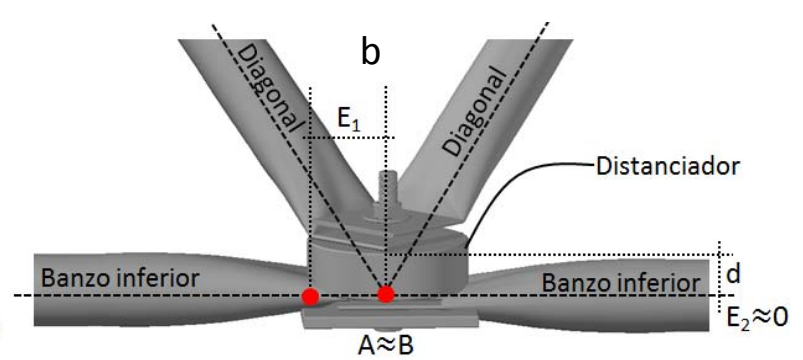

(b) Conexão com correção da excentricidade

Figura 4 - Correção da excentricidade usando distanciador (Silva et al., 2018) 
O objetivo de utilizar o distanciador é eliminar a excentricidade $E_{2}$ e fazer com que os pontos $A$ e $B$ se sobreponham na conexão, situação na qual os momentos de flexão nas ligações são reduzidos substancialmente, devido às forças normais geradas pelas diagonais com relação ao eixo central dos banzos convergirem para um único ponto.

A equação 1 mostra como é obtida o distanciador, deduzida em (Freitas, 2008), cujas variáveis são: $d$ equivale ao distanciador, $H$ é a altura da treliça tridimensional com formato piramidal, I representa o comprimento dos banzos, e $E_{1}$ é inerente ao amassamento das barras na ligação com o nó típico, por último temos a espessura $t$ da parede do tubo.

$$
d=\frac{2 H E_{1}}{l \sqrt{2}-4 E_{1}}-8 t
$$

\section{Procedimentos Experimentais}

\subsection{Características dos Protótipos}

Trabalhos anteriores com distanciadores mostraram-se eficazes (Freitas, 2008) e (Freitas et al., 2016), (Silva et al., 2018). Neste contexto, foram realizados experimentalmente seis ensaios estáticos com protótipos de $9 \times 6 \mathrm{~m}$ no Laboratório de Estruturas do Departamento de Engenharia Civil da Universidade Federal do Cariri, em parceria com o Programa de Pós-Graduação em Estruturas e Construção Civil - PECC da Universidade de Brasília.

Nesse ínterim, os resultados dos ensaios experimentais dos protótipos permitiram avaliar a resistência da estrutura com distanciadores, comparando-os com a treliça tridimensional com ligação típica através de carga versus deslocamento.

Os seis tipos de protótipos foram ensaiados com as seguintes configurações na conexão: Dois com Ligação Típica Experimental - LTE, sem a presença de distanciador; dois com Ligação Típica com Distanciador de Aço Experimental - LTDAE; por fim, dois com Ligação Típica com Distanciador reforçado com fibra de Sisal Experimental LTDSE. A Tabela 1 apresenta os detalhes construtivos dos protótipos.

Inicialmente, foram executados todos os modelos sem distanciadores LTE e ensaiados, posteriormente foram construídos os protótipos com distanciadores, sem 
aproveitamento das barras e dos parafusos utilizados nos ensaios anteriores, único material utilizado em todos os ensaios foram às chapas metálicas de reforço.

Tabela 1: Detalhes dos protótipos ensaiados no laboratório

\begin{tabular}{|c|c|c|c|c|c|c|}
\hline Tipo de & Modelo da & Dimensões & Eleme & ento ( $\mathrm{mm})$ & & ciador \\
\hline Protótipo & Conexão & $(\mathrm{cm})$ & Banzo inferior & Banzo Superior & Diagonal & $(\mathrm{mm})$ \\
\hline PROT 1 & LTE 1 & \multirow{2}{*}{$900 \times 600$} & $58 \phi 38 \times 1500$ & $38 \phi 38 \times 1500$ & $96 \phi 38 \times 1470$ & ---- \\
\hline PROT 2 & LTE 2 & & $58 \phi 38 \times 1500$ & $38 \phi 38 \times 1500$ & $96 \phi 38 \times 1470$ & ---- \\
\hline PROT 1 & LTDAE 1 & \multirow{2}{*}{$900 \times 600$} & $58 \phi 38 \times 1500$ & $38 \phi 38 \times 1500$ & $96 \phi 38 \times 1470$ & 25 \\
\hline PROT 2 & LTDAE 2 & & $58 \phi 38 \times 1500$ & $38 \phi 38 \times 1500$ & $96 \phi 38 \times 1470$ & 25 \\
\hline PROT 1 & LTDSE 1 & \multirow{2}{*}{$900 \times 600$} & $58 \phi 38 \times 1500$ & $38 \phi 38 \times 1500$ & $96 \phi 38 \times 1470$ & 25 \\
\hline PROT 2 & LTDSE 2 & & $58 \phi 38 \times 1500$ & $38 \phi 38 \times 1500$ & $96 \phi 38 \times 1470$ & 25 \\
\hline
\end{tabular}

As Figuras 5, 6 e 7 mostram os detalhes do protótipo, com a representação dos modelos de ligações utilizadas nos ensaios, e dimensões da estampagem das barras.

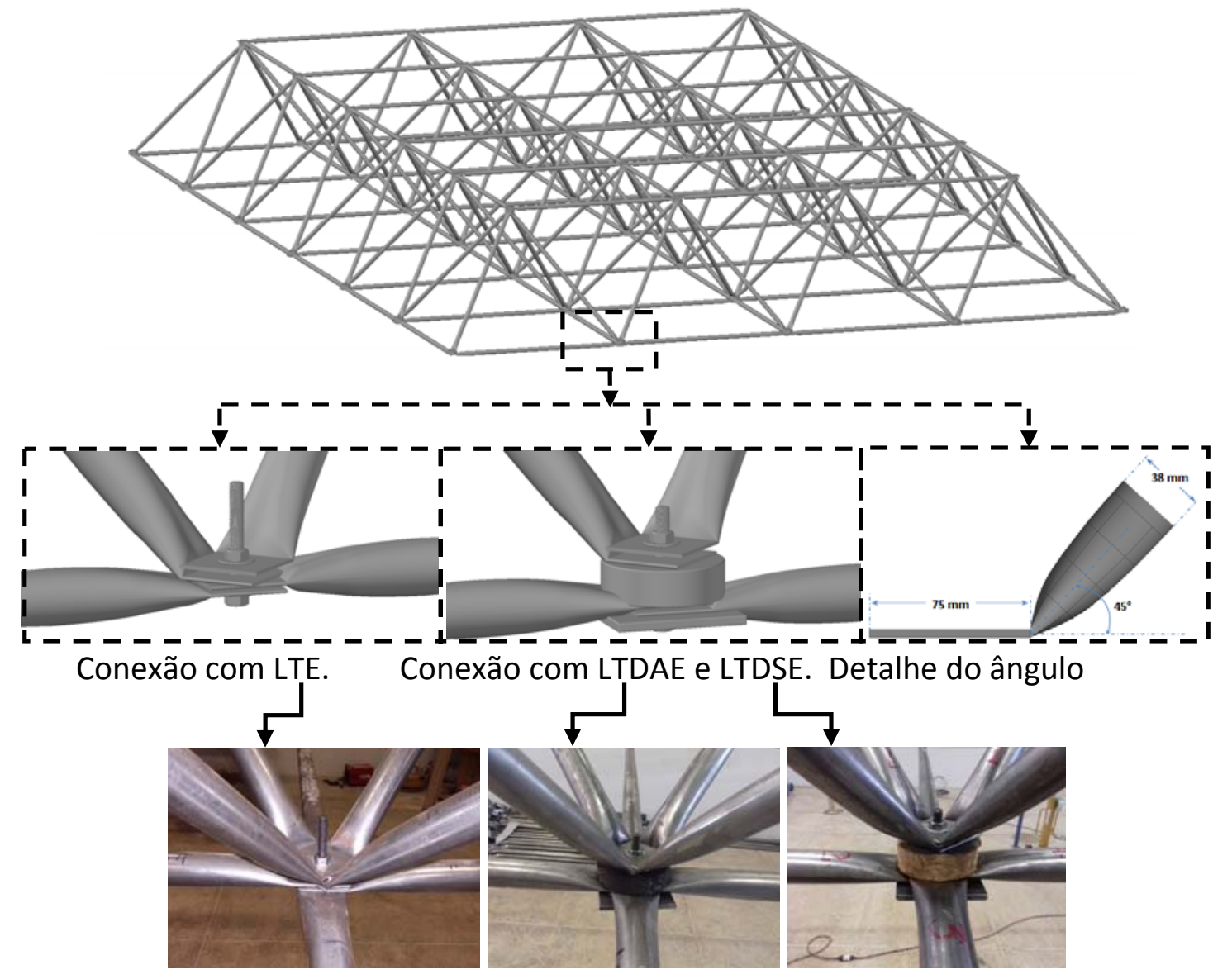

Figura 5 - Apresenta os detalhes da ligação de cada protótipo ensaiado 

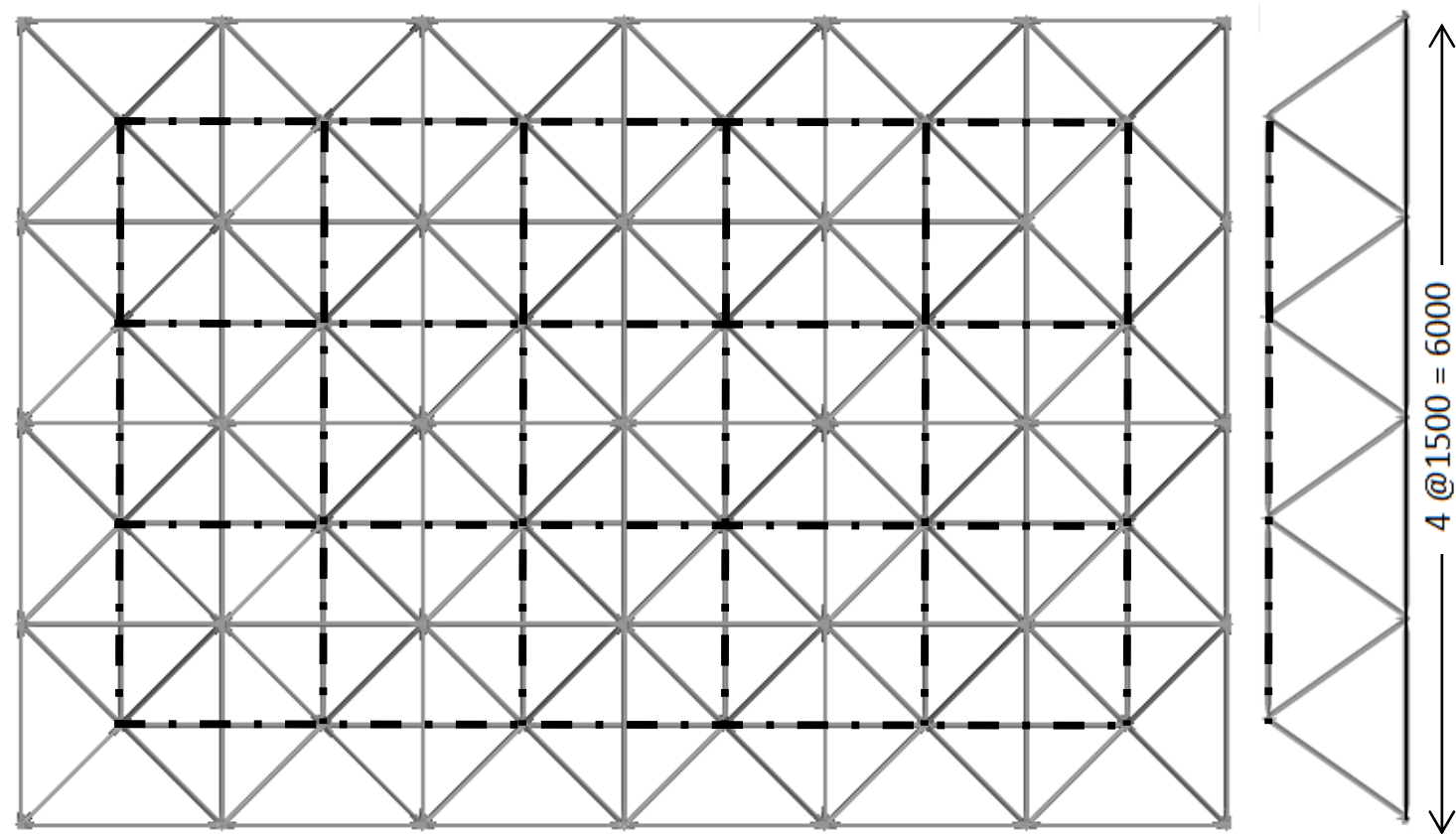

$\stackrel{1500 \mathrm{~mm}}{\longleftrightarrow}$

$45^{\circ}$

Vista do projeto em planta $x z$

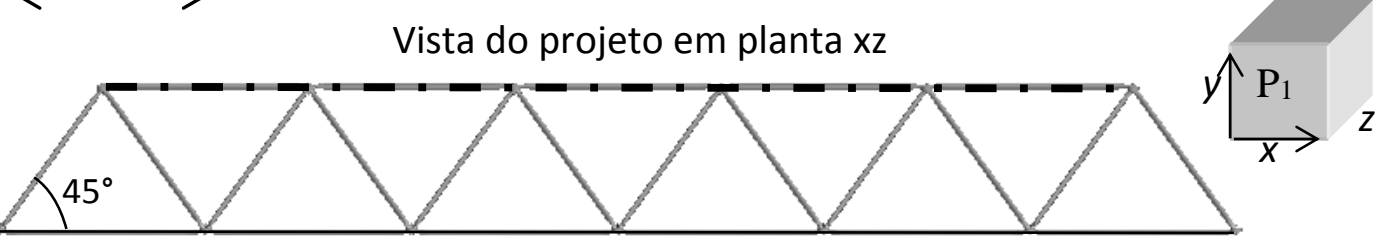

$\leftarrow$

$6 @ 1500=9000$ mm

Vista lateral do projeto no plano xy

Banzo superior - $38 @ 1500$ mm - - - - -

Banzo inferior - $58 @ 1500$ mm

Diagonais-96@1464 mm

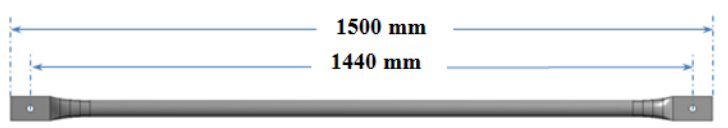

Detalhes dos 96 banzos das peças

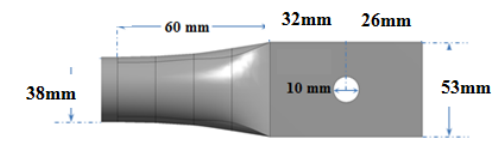

Detalhe da estampagem da peça

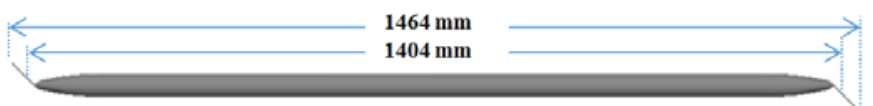

Detalhe das 96 peças das diagonais
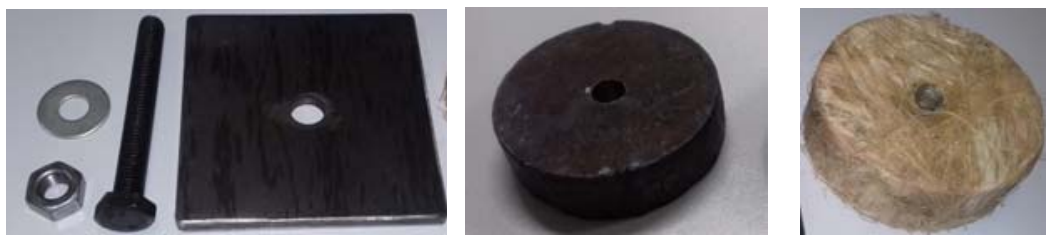

Detalhes dos parafusos, espaçadores e da chapa de aço $90 \times 90 \mathrm{~mm} \# 7 \mathrm{~mm}$

Figura 6 - Detalhes dos elementos da treliça tridimensional 


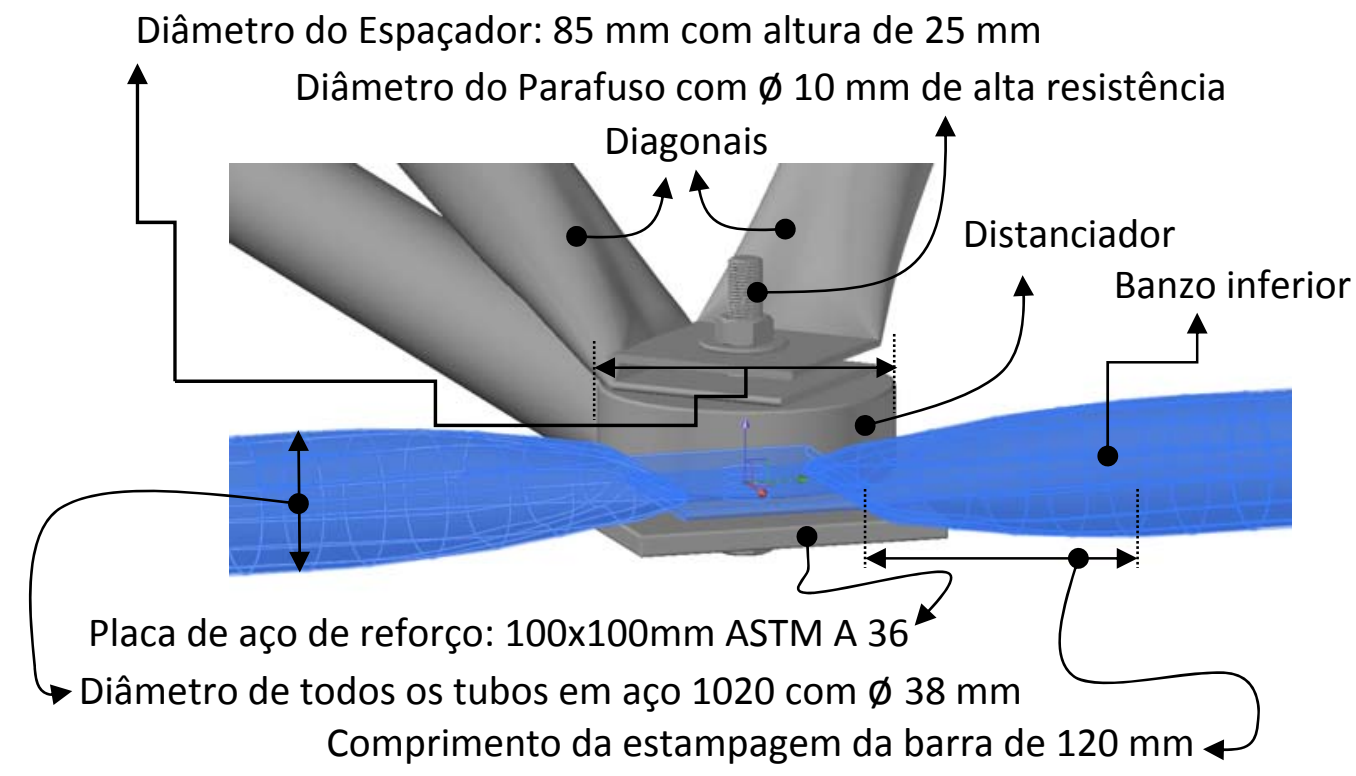

Figura 7 - Detalhe da Conexão com distanciador para correção da excentricidade

\subsection{Materiais utilizados nos protótipos}

Em todos os protótipos, foi empregado tubo de aço carbono com espessura de 1,2 mm, com propriedades químicas definidas conforme ABNT NBR 8261 (1983), formado a frio. Este processo garante a homogeneidade da chapa de aço trefilada com a solda, o que confere resistência aos tubos e garante uniformização da peça. A Figura 8 apresenta o processo de fabricação dos tubos, às bobinas são produzidas normalmente em espessuras abaixo de $3,00 \mathrm{~mm}$ e possuem tolerância dimensional conforme norma ASTM A-500 (2018).

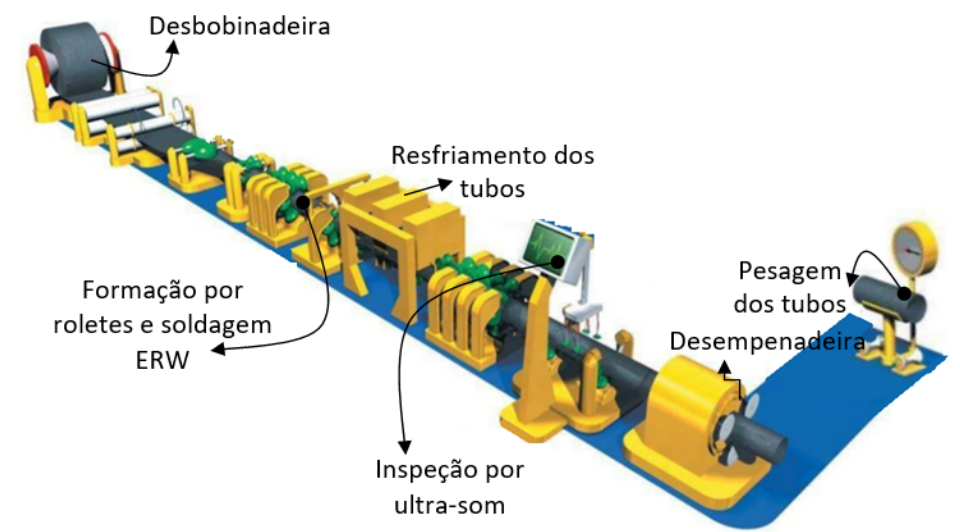

Figura 8 - Processo de produção de tubos com costura. (Chan e Cho, 2005)

Conforme apresentado na Figura 8 as etapas de fabricação dos tubos com costura resumidamente, a partir de bobinas laminadas de aço, é composto pelas seguintes fases:

Operação de desbobinamento do aço; 
$>$ Soldagem automática por resistência elétrica em alta frequência;

Calibragem;

$>$ Cortes e testes, dimensionais e de laboratório;

$>$ Ensaios não destrutivos.

Assim, para verificação da resistência à tração do aço usado nas barras das treliças espaciais, foi executado ensaio de tração segundo as diretrizes da norma ASTM A 370 (2017). Para tal, foi realizado um total de 16 ensaios com corpos-de-prova extraídos diretamente do tubo, conforme Figura 9. De modo, que a exigência da norma API 5CT (2005) fixa o local de retirada das amostras a partir de $90^{\circ}$ da linha de solda, ou seja, a partir do metal base.

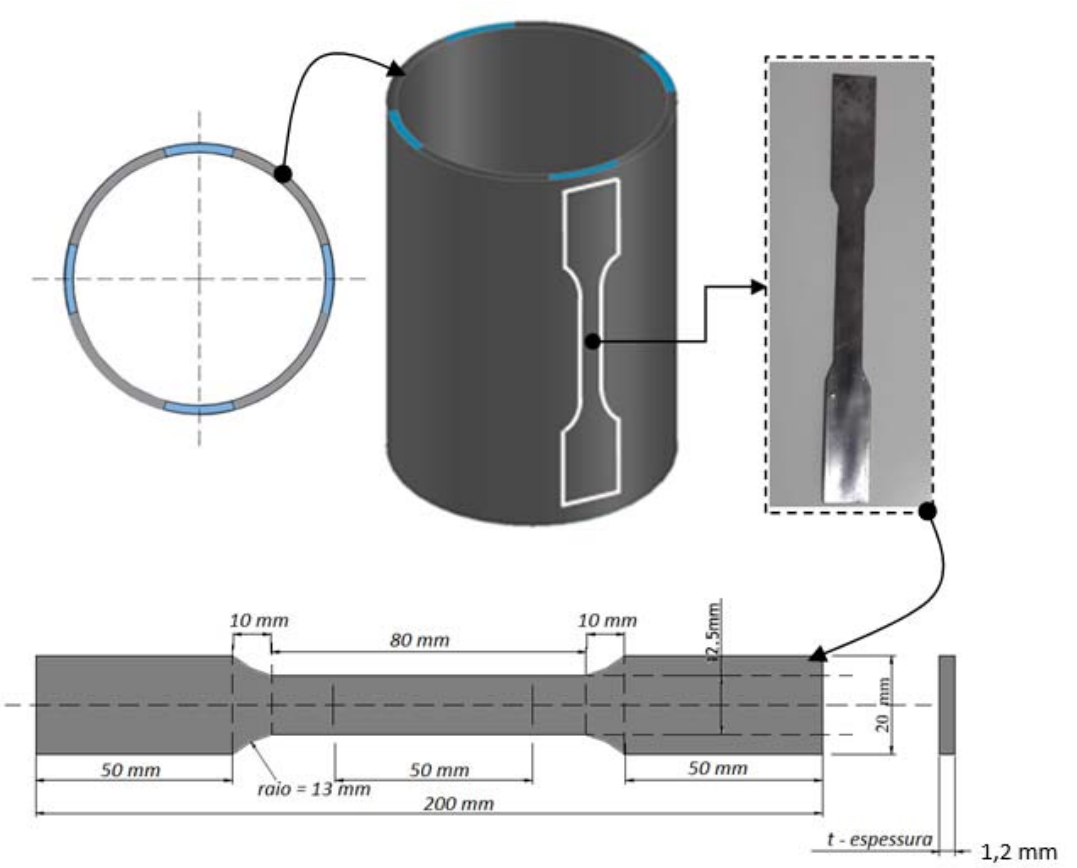

Figura 9 - Retirada de corpos de prova dos tubos para ensaio de tração uniaxial

O gráfico da Figura 10 apresenta os resultados da caracterização das amostras, para ensaios de tração. Utilizou-se uma máquina de ensaio modelo EMIC 23-100 Equipamentos e Sistemas de Ensaio Ltda., com velocidade de deslocamento de até 500 $\mathrm{mm} / \mathrm{min}$ e célula de carga com capacidade máxima de $100 \mathrm{KN}$. 


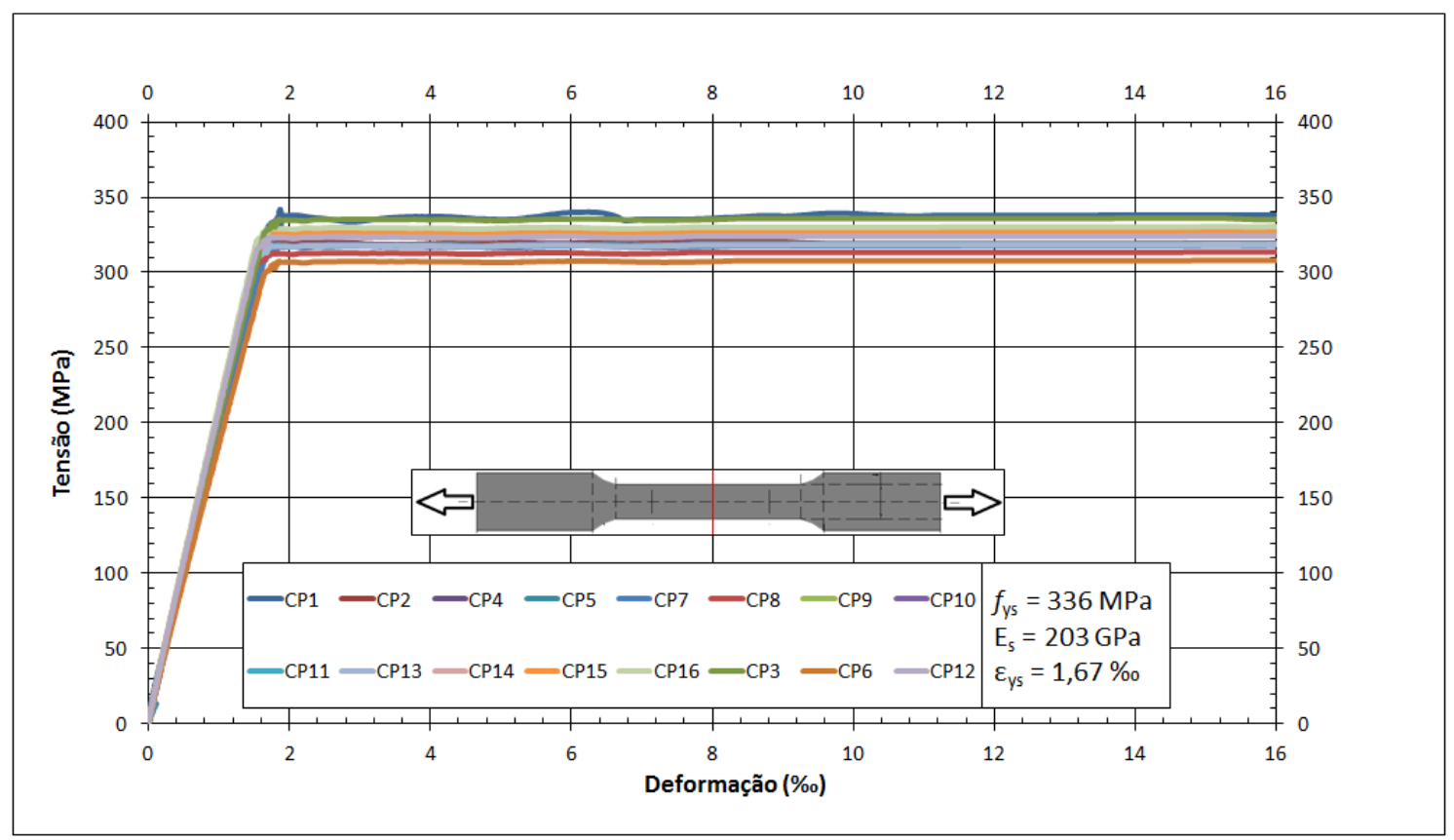

Figura 10 - Resultado do ensaio de tração do aço à temperatura ambiente

Os resultados dos ensaios à tração das barras estão dentro das especificações do fabricante com modulo de elasticidade de 203 GPa e resistência ao escoamento do aço de 336 MPa com deformação de 1,67\%. Para elaboração dos distanciadores conforme apresentado na Figura 7 procurou materiais de fácil acesso e de baixo custo, com propriedade mecânica de alta resistência à compressão.

Desse modo, foi empregado o sisal com resina de epóxi, constituído por uma fibra natural (Carneiro, 2017) de elevado módulo de elasticidade e resistência mecânica (Freitas et al., 2015). Outras vantagens desse composto é o seu baixo custo, fonte renovável e fácil disponibilidade no Brasil (Oliveira, 2007), sendo a região nordeste do país o maior exportador de sisal do mundo com $52 \%$ da produção mundial, que destina grande parte para Europa, Ásia e América do Norte (Martin et al., 2009).

O Sisal é uma espécie nativa da América Central, com nome botânico de Agave Sisalana, tradicionalmente usada na indústria têxtil, mas tem muitos outros usos. Na construção civil são utilizadas como polimento de revestimentos cerâmicos, também aplicados na substituição de amianto na composição de telhas para cobertura, usados em concretos com fibras cujos estudos mostram que a adição de fibras de sisal na matriz de base do cimento (pasta, argamassa ou concreto) aumenta significativamente a sua tenacidade e comportamento pós-fissuração. Portanto, neste trabalho foi aplicado Polímero Reforçado com Fibra de Sisal a fim de obter um distanciador leve, 
com alta resistência à compressão e com baixo custo associado, conforme detalhes do processo construtivo mostrado na Figura 11. De modo que o sisal foi colocado no molde de aço e embebido com resina de epóxi, e após duas horas foi extraído do molde, pronto para ser aplicado como distanciador da treliça tridimensional.

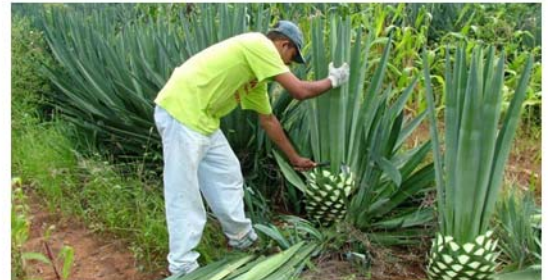

Extração da Fibra de sisal.

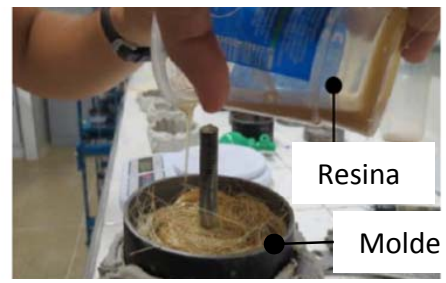

Mistura da Fibra de sisal com epóxi.

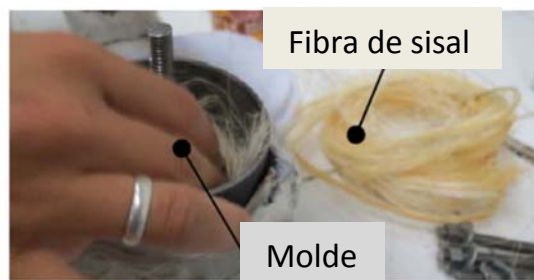

Molde do Polímero com Fibra de Sisal

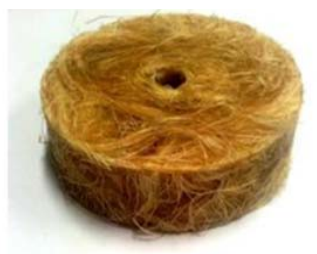

Distanciador do molde retirado do molde.

Figura 11 - Processo construtivo dos distanciadores de polímero reforçado com fibra de sisal, (Freitas et al., 2016)

\section{Ensaios Experimentais}

\subsection{Resultados dos ensaios experimentais dos distanciadores}

Para avaliar a resistência à compressão dos distanciadores proposto, foram selecionados aleatoriamente 3 distanciadores de cada modelo LTDAE e LTDSE para teste de carga estático, sem reaproveitamento destes distanciadores nos ensaios das treliças tridimensionais.

Assim, as amostras foram ensaiadas à compressão, com carga de $125 \mathrm{kN}$ com objetivo de determinar o deslocamento de cada espaçador mediante aplicação de carga. Sabendo, que caso os distanciadores tenham diminuição significativa de altura, não haverá correção da excentricidade, e o colapso da estrutura ocorrerá na ligação. A Figura 12 apresenta os elementos espaçadores sendo ensaiados, já na Figura 13 é apresentado os valores de carga versus deslocamentos. 

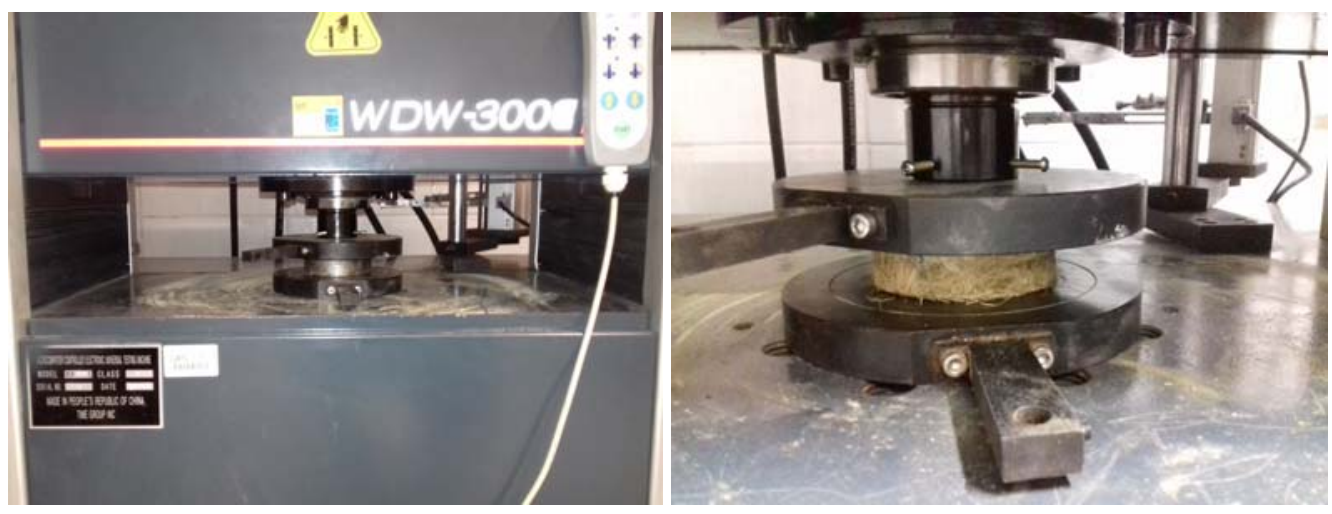

Figura 12 - Elementos distanciadores submetidos à força de compressão

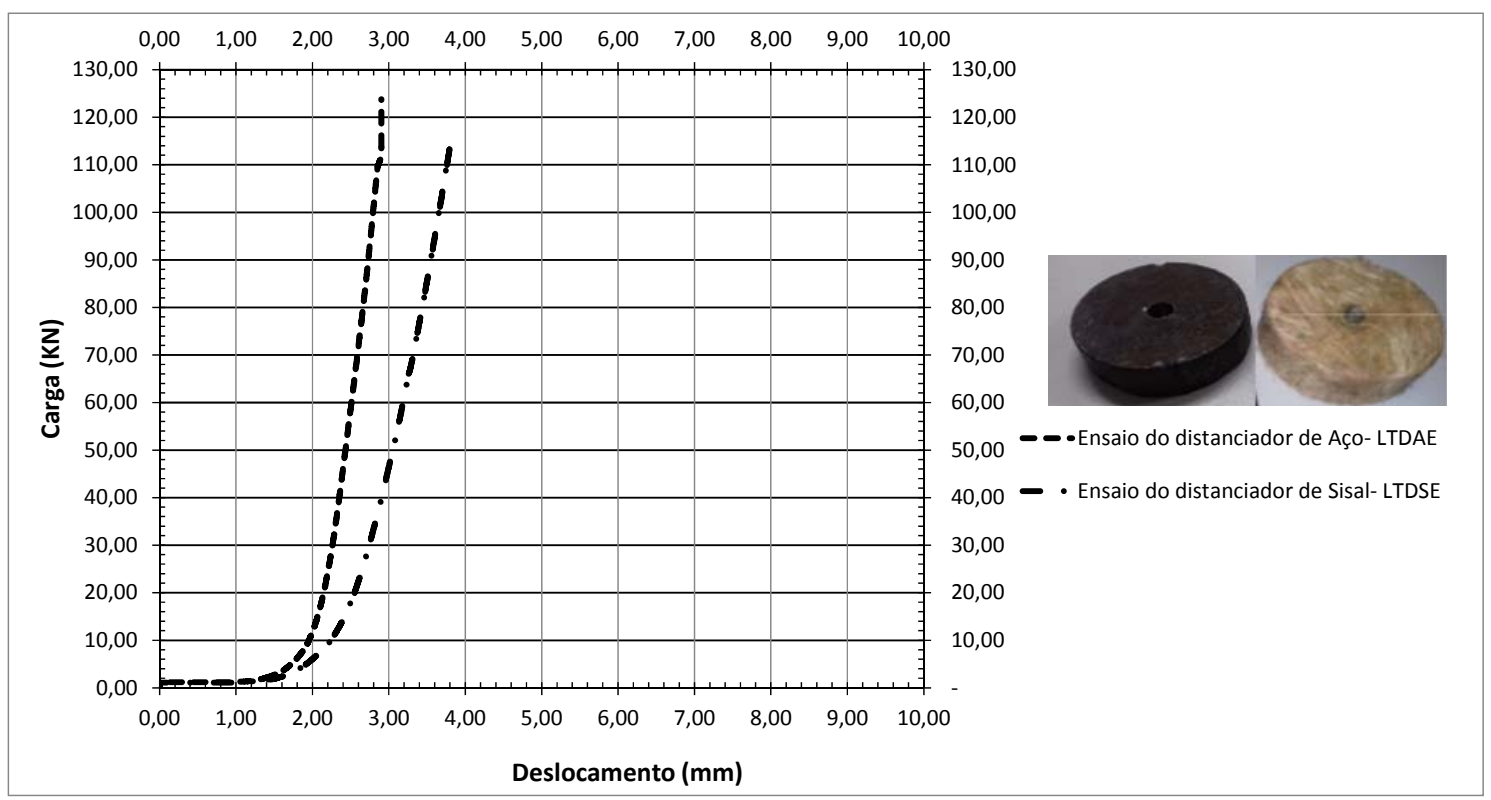

Figura 13 - Resultado do ensaio do distanciador submetidos à força de compressão

Os resultados mostram que os distanciadores LTDSE tiveram comportamento similar aos LTDAE com acréscimo de $22 \%$ de deslocamento. Desse modo, será esperado que nos ensaios experimentais das treliças tridimensionais com distanciadores, os prototípicos com LTDSE tenham deflexão menor que o prototípico com LTDAE devido o menor peso próprio. Espera-se também que os prototípicos com distanciadores LTDSE apresentem resultados semelhantes aos prototípicos com LTDAE, porém com carga de ruptura superior aos LTDAE devido ao menor peso do distanciador.

\subsection{Metodologia da montagem das treliças tridimensionais}

A montagem das treliças tridimensionais aconteceu de forma idêntica, com mudança apenas nos distanciadores nas ligações, a estrutura treliçada foi fixada em colunas de perfis metalicos tipo trilho 57 fabricado segundo recomendações da norma ABNT NBR 
7590 (2012) com altura de 1300 mm e engastados no piso do laboratório com placa de base por meio de paraboltes com resina epoxídica.

Já as ligações foram compostas por parafusos, porcas, arruelas, distanciadores e chapas de reforço, dependendo do protótipo ensaiado, conforme apresentado na Figura 14.

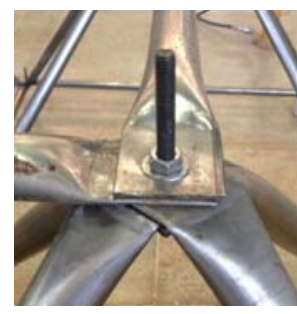

Ligação LTE

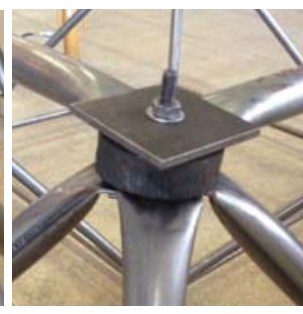

Ligação LTDAE

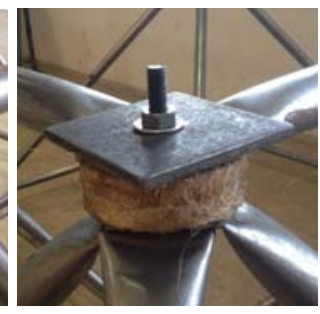

Ligação LTDSE

Figura 14 - Tipos de ligações das treliças tridimensionais ensaiadas no laboratório

Os protótipos foram montados no piso do laboratório em uma sequência específica para garantir a simetria da estrutura. A força de pretensão nos parafusos foi controlada com um torquímetro de vareta com intensidade de $50 \mathrm{Nm}$. Após a montagem a estrutura foi colocada na posição final sobre os pilares com o auxílio de um guincho hidráulico.

A aquisição de dados dos ensaios experimentais foi obtida por meio de leitura das cargas, em painéis digitais conectados às células de cargas inicialmente calibradas, e deflectômetros analógicos dispostos nas ligações onde foram aplicados os carregamentos. O sentido de aplicação de carga ocorreu na mesma direção da força gravitacional, de forma que a estrutura foi puxada para baixo pelos macacos hidráulicos que estavam fixados no piso do laboratório.

Os detalhes da montagem do sistema de aquisição de dados para leitura do ensaio esta apresentado na Figura 15.

A precisão dos medidores de deslocamento tipo deflectômetro era da ordem de 0,01 mm e a capacidade de leitura $30,00 \mathrm{~mm}$, sendo necessário reposicionar várias vezes durante o ensaio. Já as células de cargas tinham capacidade de $50 \mathrm{kN}$ e foram instalados no topo dos eixos dos macacos hidráulicos através de parafusos. A ligação entre a célula de carga e o protótipo foi com cordoalhas de aço espaçadas por um molde de madeira maçaranduba a fim de evitar a concentração de tensões na ligação 
do protótipo e redistribuir os esforços mais uniformemente. A pressão dos macacos hidráulicos era controlada por um conjunto motor bomba, que possuíam quatro válvulas de fluxo de óleo para distribuir o fluido nos elementos hidráulicos, e uma válvula geral para controlar a intensidade do bombeamento. As leituras eram realizadas a cada passo de carga de 0,25 kN. O carregamento foi aumentando gradualmente até o colapso global da estrutura, a fim de garantir o carregamento estático e evitar instabilidades na estrutura. Já os resultados foram dispostos em uma planilha do Excel com valores de carga e deslocamento.

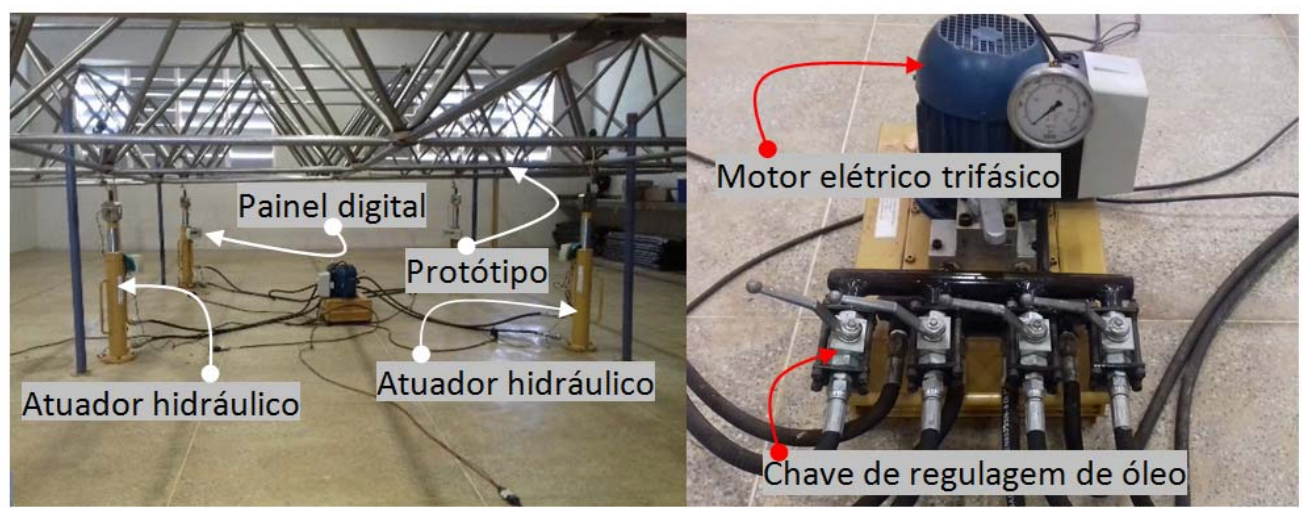

(a) Detalhes do sistema de ensaio
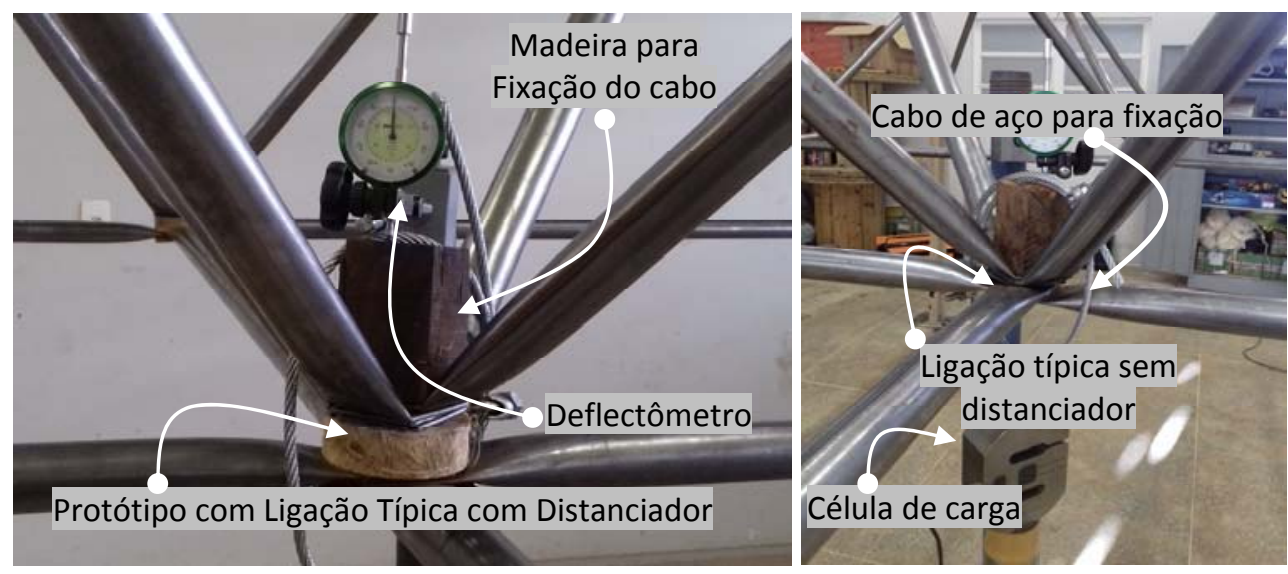

(b) Detalhe do deflectômetro na ligação típica onde foi aplicado o carregamento

Figura 15 - Detalhes do sistema de ensaio das treliças tridimensionais

\subsection{Resultados dos ensaios experimentais das treliças tridimensionais}

O carregamento representado nos gráficos consiste no somatório das cargas aplicadas individualmente pelos quatro macacos hidráulicos nos pontos indicados pela Figura 16. Já o deslocamento contempla a média aritmética dos quatro pontos de leitura, apresentado nos gráficos de carga versus deslocamento, para cada protótipo ensaiado. 


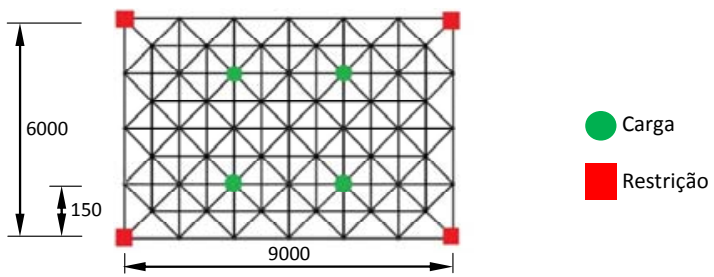

Figura 16-Vista em planta do modelo ensaiado

\subsection{Resultados da Ligação Típica LTE}

Os dois ensaios realizados com os protótipos LTE1 e LTE2 apresentaram resultados finais similares, devido ao processo de montagem, instrumentações e modos de aplicação de carga. O ensaio do protótipo LTE1 evidenciou o colapso da treliça com o carregamento total aplicado de $30,9 \mathrm{kN}$, apresentando deslocamento médio de 119,80 $\mathrm{mm}$. Já os valores obtidos no segundo ensaio LTE2 o colapso da estrutura ocorreu de forma semelhante ao primeiro, com ruptura da ligação típica nos banzos compridos com as diagonais de extremidade da treliça, onde os esforços de compressão tiveram maior intensidade. O valor da carga na ruina foi de $30,4 \mathrm{kN}$ e deflexão de $119,5 \mathrm{~mm}$. Os resultados dos ensaios estão indicados na Figura 17.

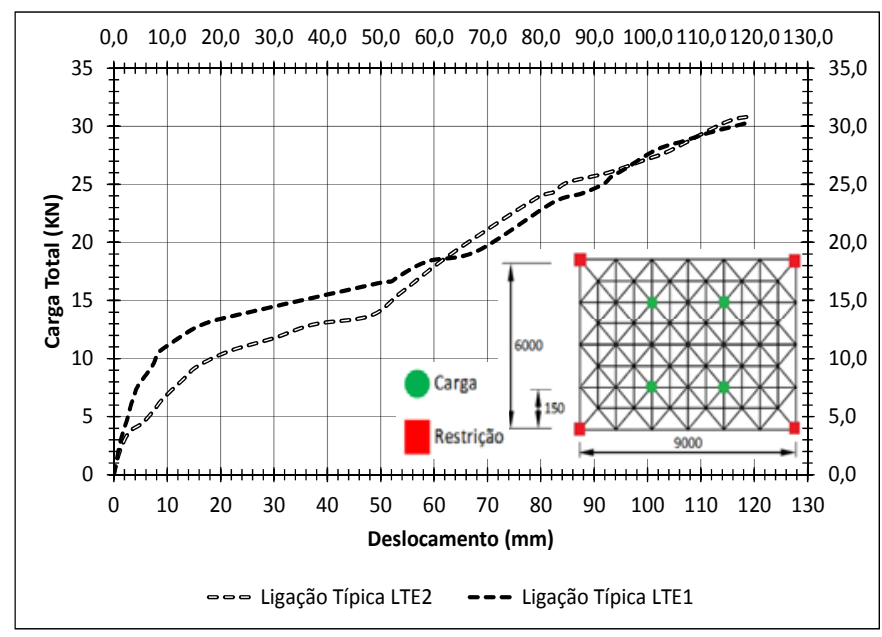

Figura 17 - Ensaio dos protótipo LTE1 e LTE2

\subsection{Ensaio da Ligação Típica com Distanciador de Aço- LTDAE}

Os ensaios com distanciadores de aço utilizados nos dois protótipos mostraram a eficiência na correção das ligações típicas, no espécime LTDAE1 a carga de ruptura foi de $42,4 \mathrm{KN}$, e o deslocamento médio foi de $99,8 \mathrm{~mm}$, já no segundo modelo LTDAE2 a carga de ruptura foi $41,5 \mathrm{KN}$ com deslocamento de 107,2 mm. A Figura 18 apresenta os resultados dos dois ensaios dos espécimes através do gráfico carga versus deslocamentos. 


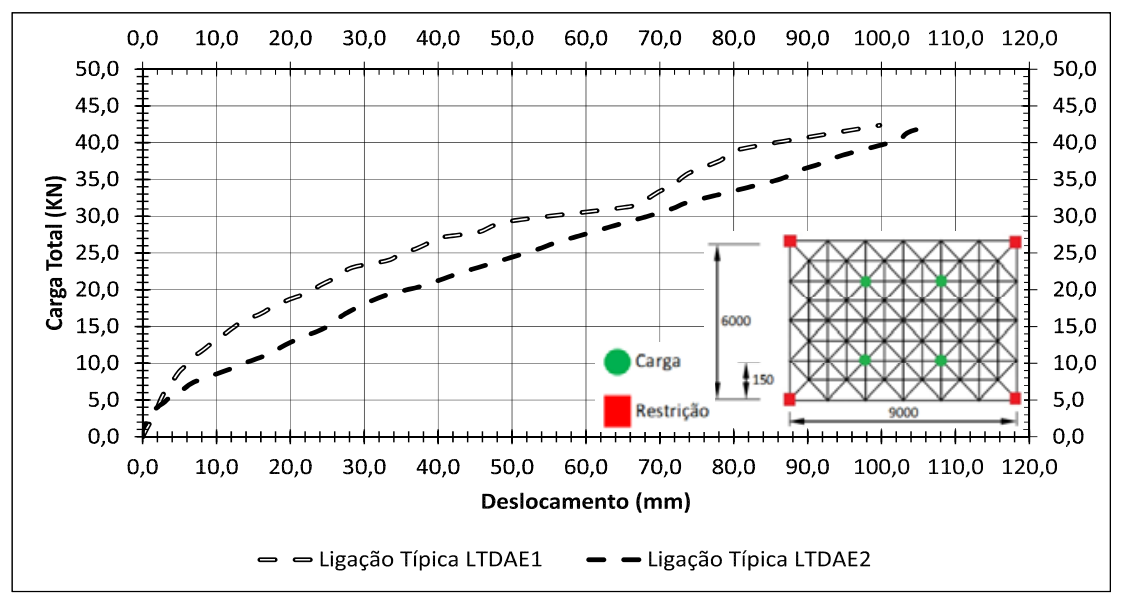

Figure 18 - Resultados do ensaio dos protótipo LTDAE1 e LTDAE2

\subsection{Ligação Típica com Distanciador de Sisal- LTDSE}

Os protótipos construídos com ligações do tipo LTDSE apresentaram os seguintes resultados: O modelo LTDSE1 apresentou carga de ruptura igual a $42 \mathrm{KN}$ e deslocamento médio de 114,5 $\mathrm{mm}$. Semelhantemente, o protótipo LTDSE2 obteve carga de ruptura equivalente a $45 \mathrm{KN}$ e deslocamento médio $95,00 \mathrm{~mm}$. Os resultados estão dispostos no gráfico da Figura 19. A Figura 20 mostra o mecanismo de colapso.

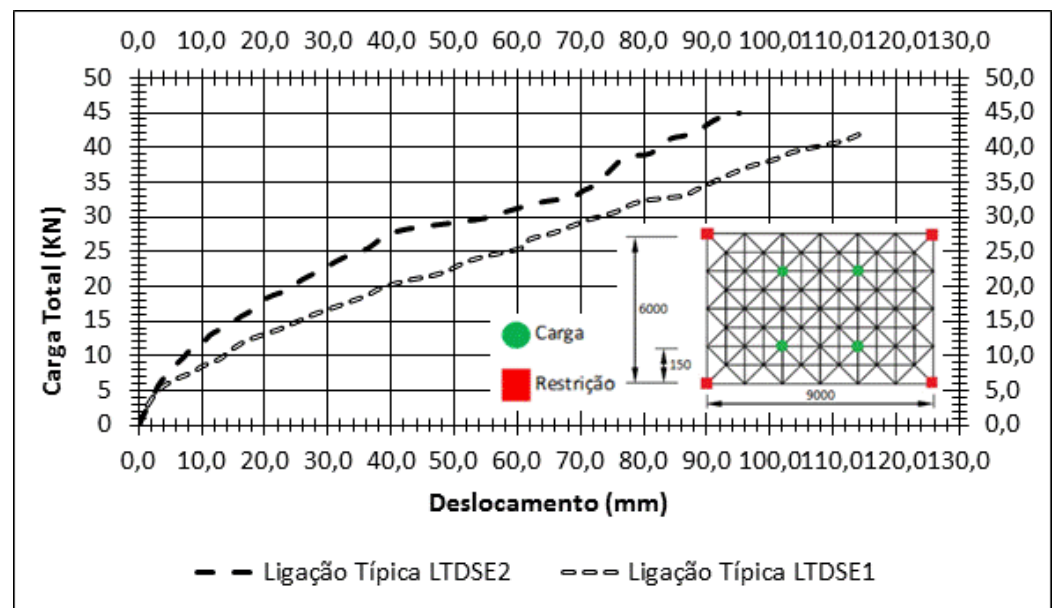

Figura 19 - Resultados dos ensaios dos modelos LTDSE1 e LTDSE2

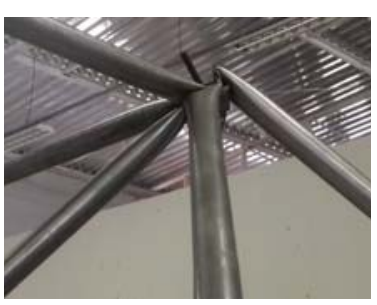

Ligação LTE

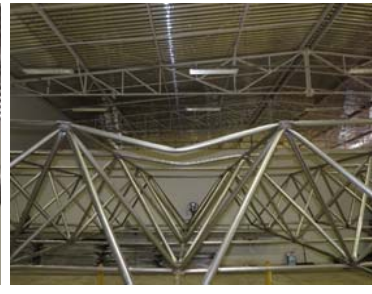

Ligação LTDAE

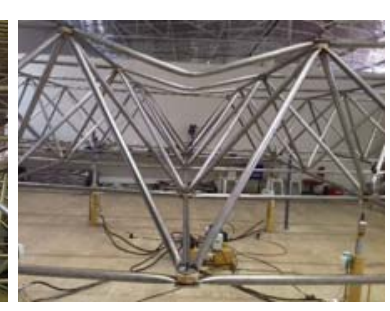

Ligação LTDSE

Figura 20 - Detalhe do colapso de todos os protótipos

A Figura 21 apresenta todos os resultados dos ensaios experimentais das treliças tridimenisais. Onde mostra que a treliça LTDSE obteve o mehor resultado. 


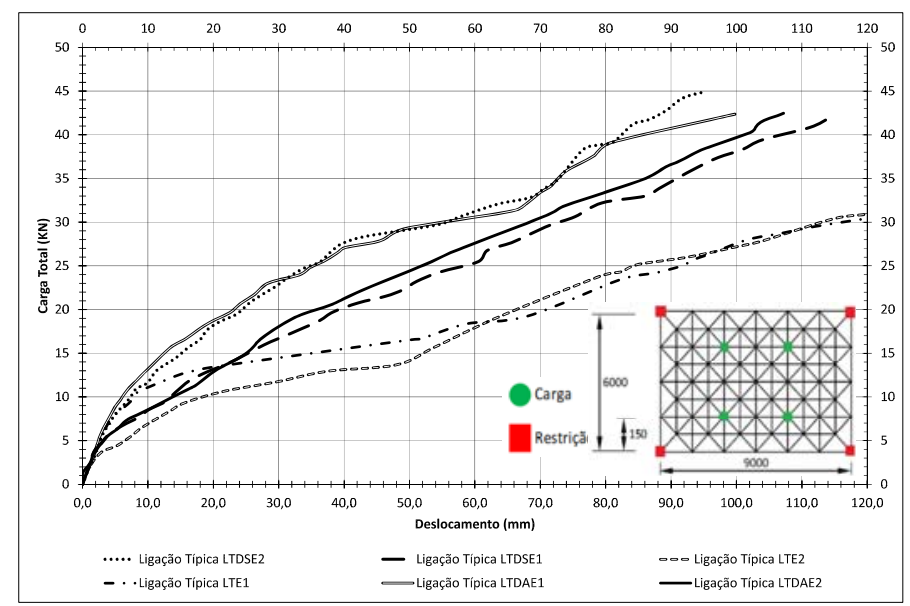

Figura 21- Resultado dos ensaios da treliça tridimensional

Para a estrutura da treliça tridimensional com ligação típica, foi calculada carga de colapso através da aplicação de normas: ABNT NBR 8800 (2008), AISC- LRFD (2010) e EUROCODE (2004). Cujo, modelo de cálculo foi considerado barra birrotulada. Já os valores obtidos foram: ABNT NBR 8800 (2008) 62 kN, AISC- LRFD (2016) 62,95 kN e EUROCODE (2004) 59,87 KN. Dessa forma, fica claro que as normas não consideram a excentridade da barra devido estampagem da ligação. O ponto mais preocupante é que o colapso acontece com carga menor que o indicado nas normas com valor experimental médio de $30,65 \mathrm{kN}$, indo contra a segurança estrutural.

\section{Conclusões}

Na estrutura de nó típico LTE, o colapso ocorreu localmente nos nós, antes que os membros atingissem a capacidade resistente à compressão, devido à perda de rigidez causada pela estampagem das barras, em conjunto com o incremento do momento fletor, oriundo da excentricidade. Para os nós modificados LTDAE, LTDSE, o colapso ocorreu globalmente, devido ao esgotamento da capacidade resistente das barras comprimidas, após atingirem a carga de compressão crítica. Os resultados evidenciam a eficácia dos distanciadores como elementos de correção da excentricidade, com ganho de capacidade resistente entorno de $48 \%$. O distanciador LTDSE obteve o melhor resultado conforme esperado com ganho de resistência próximo ao LTDAE com custo reduzido e ecologicamente correto.

\section{Agradecimentos}

Os autores agradecem a UFCA e UnB. CAPES, CNPQ e Funcap pelo apoio financeiro. 


\section{Referências bibliográficas}

ANSI/AISC 360-16. Specification for Strututural Stell Buildings, Americam Stitutive od steel Construction, New York, NY, June 23 of 2016.

ASTM A370-17a - Standard Test Methods and Definitions for Mechanical Testing of Steel Products, ASTM International, West Conshohocken, PA, 2017.

ASTM A500 / A500M-18- Standard Specification for Cold-Formed Welded and Seamless Carbon Steel Structural Tubing in Rounds and Shapes, ASTM International, West Conshohocken, PA, 2018.

Associação Brasileira de Normas Técnicas. NBR 8800 - Projeto de estruturas de aço e de estruturas mistas de aço e concreto de edifícios. Rio de Janeiro, 2008.

Associação Brasileira de Normas Técnicas. NBR 8261 - Tubos de aço-carbono, formado a frio, com e sem solda, de seção circular, quadrada ou retangular para usos estruturais. Rio de Janeiro, 1983.

Associação Brasileira de Normas Técnicas. NBR 7590 - Trilho Vignole - Requisitos. Rio de Janeiro, 2012.

Arekar, V. A. e Bhavsar, B. B. (2013) Analytical Study of MERO Connector in Double Layer Grid Structure, 2(2), p. 35-42.

Bezerra, L. M. et al. (2009) Increasing load capacity of steel space trusses with end-flattened connections, Journal of Constructional Steel Research. Elsevier Ltd, 65(12), p. 2197-2206. doi: 10.1016/j.jcsr.2009.06.011.

Carneiro, J. L. dos S. (2017) Caracterização acessos de sisal usando descritores da planta e da fibra. Universidade Estadual de Feira de Santana.

Casanova, P. A. A. (2015) Estudo Numérico-Experimental de Treliças Espaciais Feitas com Tubos de Aço com Ponta Amassada e Espaçadores de Madeira Para Corrigir as Excentricidades nos Nós de Ligação. Universidade de Brasília.

Chan, S. L. e Cho, S. H. (2005) Second-order P delta analysis and design of angle trusses allowing for imperfections and semi-rigid connections., Advanced Steel Construction, 1(1), p. 169-183.

El-Shami, M., Mahmoud, S. e Elabd, M. (2016) Effect of floor openings on the capacity of composite space trusses, Journal of King Saud University - Engineering Sciences. King Saud University. doi: 10.1016/j.jksues.2016.03.002.

Freitas, C. A. S. et al. (2014) Numerical investigation of the space-truss with reinforce of the stamped connection after calibration model in experimental study ., 1(May), p. 17.

Freitas, C. A. S. et al. (2015) Polymer Composite with Sisal Fiber used for Node Reinforce in Space-Truss With Stamped Connection, Applied Mechanics and Materials (Volumes 719-720), p. 202-205. doi: 10.4028/www.scientific.net/AMM.719-720.202.

Freitas, C. A. S. et al. (2016) New experimental results of the research on reinforced node in space truss, Advanced Steel Construction Vol. 13, No. 1, 13(January), p. 30-44. doi: 10.18057/IJASC.2017.13.1.

Freitas, C. A. S., Bezerra, L. M. e Silva, R. S. Y. C. (2011) Numerical and Experimental Study of Steel Space Truss with Stamped Connection, 5(6), p. 494-504.

Freitas, C. A. S. de (2008) Análise Teórico-Experimental da Conexão Estampada de Treliça Espacial de Aço Sob Carregamentos Estático e Cíclico. Universidade de Brasília. 
Fu, F. (Structural engineer) Structural analysis and design to prevent disproportionate collapse 2016.

Gioncu, V. (1985) Instability Problems in Space Structures, 1, p. 169-183.

Hill, C. D., Blandford, G. E. e Wang, S. T. Post-buckling analysis of steel space trusses., Journal of Structural Engineering, 115(4), p. 900-919 1989.

Kumar, N. e Rajakumara, H. N. Study of Using Waste Rubber Tyres in Construction of Bituminous Road, 7(5), p. 23-27, 2016.

Lanik do Brasil Estruturas Espaciais, Lanik do Brasil. Available at: http://www.lanikdobrasil.com.br/br/estruturas-espaciais.html (Acessado: 29 de dezembro de 2017).

Magalhães, J. R. M. de e Malite, M. Treliças metálicas espaciais: alguns aspectos relativos ao projeto e à construção, Cadernos de engenharia de estruturas, 9928, p. 30. 1998.

Makowski, Z. S. (1972) Estructuras espaciales de acero. $2^{\circ}$ ed. Editorial Gustavo Gili, Barcelona. Martin, A. R. et al. Caracterização química e estrutural de fibra de sisal da variedade Agave sisalana, Polímeros, 19(1), p. 40-46. doi: 10.1590/S0104-14282009000100011 2009.

Martin, R. e Delatte, N. J. Another Look at Hartford Civic Center Coliseum Collapse, Journal of Performance of Constructed Facilities, 15(1), p. 31-36. doi: 10.1061/(ASCE)08873828(2001)15:1(31), 2001.

Nogueira, Wilson; Varellada, Claudia. Sambódromo de Manaus desaba e fere 25. Folha de São Paulo, São Paulo, 21 ab. 1994, p. 1.

Oliveira, J. C. de Desenvolvimento de Materiais e Processos para Compósitos Termoplástico com Fibras Naturais, p. 291. doi: 616.89-008.47:616,2007.

Prakash, J. et al. Optimization of Tire Design and Construction Parameters for Handling, Simulation Driven innovation HCT 2012, p. 7, 2012.

Ramaswamy, G. S., Mick, E. e Suresh, G. R. Analysis, Design and Construction of Steel Space Frames. Thomas Tel. London 2012.

Sampaio, T. S. Análise numérica, via mef, de ligações em treliças metálicas espaciais, Universidade de São Paulo. Universidade de São Paulo, 2004. (Dissertação de Mestrado).

Sander, A. e Souza, C. De Análise Teórica e Experimental de Treliças Espaciais, Caderno de engenharia de Estruturas, n.20(São Carlos), p. 31-61, 2006.

Siddique, R. e Naik, T. R. Properties of concrete containing scrap-tire rubber - An overview, Waste Management, 24(6), p. 563-569. doi: 10.1016/j.wasman.2004.01.006, 2004.

Silva, V.W. et al. Experimental analysis of steel space trusses whit correction of the stamped connection with glass fiber reinforced polymer space. International Jounal Engenering Sciences \& Research Technology, 7(6), 117-127.

Souza, A. S. C. de Análise teórica e experimental de treliças espaciais. Universidade de São Paulo, 2003 (Tese de Doutorado).

Souza, a. S. C. et al. A Strategy of Numerical Analysis of Space Truss Connections with Stamped Bar Ends, International Journal of Space Structures, 23, p. 143-152. doi: 10.1260/026635108786261027, 2009.

Wei, J. peng, Tian, L. min e Hao, J. ping Improving the progressive collapse resistance of longspan single-layer spatial grid structures, Construction and Building Materials. Elsevier Ltd, 171, p. 96-108. doi: 10.1016/j.conbuildmat.2018.03.126, 2018.

Zeitschrift, G. et al. Theme IIIb : Space structures, Ein Dienst der ETH-Bibliothek, 2018. 